Abstract 156 Table 1 Multivariate logistic regression analysis

\begin{tabular}{lllll}
\hline \multicolumn{1}{c}{ Variables } & OR & \multicolumn{2}{c}{$95 \%$ CI } & Pvalue \\
\hline High Cyr61 level & 7.822 & 2.224 & 41.138 & 0.002 \\
Serositis & 8.244 & 1.854 & 36.663 & 0.006 \\
Anti-RNPpositivity & 3.902 & 1.067 & 14.267 & 0.040 \\
Renal disorders & 0.174 & 0.044 & 0.689 & 0.013 \\
Anti-dsDNA positivity & 0.171 & 0.046 & 0.636 & 0.008 \\
\hline
\end{tabular}

Results Group A did not differ from control group. Group B had higher titers of anti-ABCA1 antibodies $(p=0.004)$, with 4 patients showing positive anti-ABCA1 titers (11.4\%). In group $\mathrm{B}$, anti-ABCA1 antibodies titers tend to negatively correlate with HDL $(p=0.06)$ and apoliporoteinA-I levels $(p=0.04)$. In both groups, anti-HDL antibodies did not correlate with antiABCA1 titers.

Conclusions This is the first report of naturally occurring antibodies against ABCA1. These antibodies are increased in patients with SLE with at least 4 SLICC classification criteria. Future studies will determine their pathogenic role.

This work was supported by the Portuguese Foundation for Science and Technology via the post-doctoral SFRH/BPD/ 112411/2015 and Fundação Oriente.

\section{CONTRIBUTORS TO DISEASE FLARES AMONG FILIPINO PATIENTS WITH SLE}

ME Fernandez, MFJ Edar, S Navarra. University of Santo Tomas Hospital, Internal MedicineRheumatology, Manila, Philippines

\subsection{6/lupus-2017-000215.158}

Background and aims SLE disease flares significantly contribute to morbidity and mortality in SLE. This study describes the characteristics and contributing factors to disease flares in a cohort of Filipino SLE patients.

Methods Included were SLE patients with disease flare seen consecutively from January 2012 to December 2015 at the Lupus Clinics of University of Santo Tomas (UST) Hospital, Manila, Philippines. Demographics, organ involvement and SLE flare severity by SELENA-SLEDAI Flare Index (SFI) were described. Contributing factors to flare were identified based on physician assessment notes and patient responses to the Life Experiences Survey (LES).

Results There were 100 disease flares in 73 patients (68 females). Mean age at SLE diagnosis was 25.15 \pm 8.57 years (4-43), disease duration at each flare occurrence was 7.40 $\pm 4.42(<1-21)$ years. Flares were severe in 60 , mild to moderate in 40. Organ involvement included renal in 47 (32.41\%), mucocutaneous 40 (27.59\%), musculoskeletal 26 (17.93\%), vasculitis 11 (7.59\%), hematologic 11 (7.59\%), neurologic 6 (4.14\%), ocular $(32.07 \%)$ and cardiopulmonary 1
(0.68\%). Stress and infection in 35 (30.97\%) each, were the leading contributors to flare. Others included non-compliance in $18(15.93 \%)$, excess sun exposure 7 (6.20\%), pregnancy 3 (2.66\%), fetal loss $3(2.66 \%)$, surgery and drugs during 1 $(0.88 \%)$ flare occurrence each, and unknown in $10(8.85 \%)$.

Conclusions Renal, mucocutaneous and musculoskeletal systems were most commonly involved in a disease flare. Stress and infection were the leading factors contributing to a flare. These findings underscore need for holistic management approach in SLE, integrating effective disease control with patient education

\section{NEUTROPHIL-TO-LYMPHOCYTE RATIO AND SYSTEMIC LUPUS ERYTHEMATOSUS: A NEW PARAMETER FOR DISEASE ACTIVITY ASSESSMENT?}

${ }^{1} \mathrm{H}$ Gunawan*, ${ }^{1} \mathrm{~A}$ Awalia, ${ }^{1} \mathrm{~J}$ Soeroso. ${ }^{1}$ Airlangga University, Internal Medicine Rheumatology Division, Surabaya, Indonesia

\subsection{6/lupus-2017-000215.159}

Background and aims Systemic Lupus Erythematosus (SLE) is a complex autoimmune disease characterised by enhanced apoptosis in conjunction with high levels of autoantibodies and deregulated cytokine productions. It contributes to immune dysfunction, tissue inflammation, and organ damage. Neutrophil to Lymphocyte ratio (NLR) is a promising marker in SLE, but its relationships with SLE's disease activity in Indonesian population has not been evaluated.

To investigate the correlation between NLR and SLE disease activity.

Methods A cross sectional study with consecutive sampling technique was conducted with 70 Indonesian SLE patients in Dr. Soetomo Hospital Surabaya at May 2016-July 2016. Peripheral blood count was evaluated during assessment with flowcytometry technique and disease activity was evaluated with Systemic Lupus Activity Measure (SLAM) score. Data analysis was done with Spearman's correlation rank test and ROC curve using SPSS v22.0.

Results There were 19 patients with SLAM score $<7$ (group 1) and 51 patients with SLAM score $\geq 7$ (group 2). We found that lymphocyte count and NLR was statistically significant between groups $\left[\begin{array}{lllll}1.58 & (0.66-2.73)\end{array}\right)$ vs $0.95 \quad(0.14-3.49)$; 
Abstract 159 Tabel 1 Basic characteristics of the study

\begin{tabular}{|c|c|c|c|}
\hline Parameter & $\begin{array}{c}\text { SLAM }<7 \\
(n=19)\end{array}$ & $\begin{array}{c}\text { SLAM } \geq 7 \\
(\mathrm{n}=51)\end{array}$ & p \\
\hline \multicolumn{4}{|l|}{ Sex } \\
\hline Male & 2 & 7 & \\
\hline Female & 17 & 44 & \\
\hline Age (years) & $35(19-63)$ & $30(14-60)$ & 0.22 \\
\hline Duration of discase (ycars) & $2.5(0.33-18)$ & $1.33(0.15-20)$ & 0.16 \\
\hline Hemoglobin $(\mathrm{g} / \mathrm{dL})$ & $12.6(8.93-14.6)$ & $9.50(2.90-13.9)$ & $0.15^{\prime}$ \\
\hline Leukocytes $\left(\times 10^{3} \mu / \mathrm{L}\right)$ & $7.23(3.73-16.38)$ & $6.40(1.02-17.04)$ & 0.96 \\
\hline Neutrophils $\left(x 10^{3} \mu / \mathrm{L}\right)$ & $4.76(11.98)$ & $4.92(0.48-15.52)$ & 0.41 \\
\hline Lymphocytes $\left(\times 10^{3} \mu / \mathrm{L}\right)$ & $1.58(0.66-2.73)$ & $0.95(0.14-3.49)$ & 0.01 \\
\hline Platelets $\left(\times 10^{3} \mu / \mathrm{L}\right)$ & $268(175-370)$ & $220(4.68-687)$ & 0.39 \\
\hline Random plasma glucose $(\mathrm{mg} / \mathrm{dL})$ & $87(73-212)$ & $101(62-232)$ & 0.40 \\
\hline $\mathrm{BUN}^{+}(\mathrm{mg} / \mathrm{dL})$ & $12(7.0-23.3)$ & $13(4-107)$ & $0.73^{\prime}$ \\
\hline Creatinine serum $(\mathrm{mg} / \mathrm{dL})$ & $0.91(0.39-1.32)$ & $0.85(0.32-13.6)$ & 0.08 \\
\hline Albumin (g/dL) & $4.10(2.0)$ & $3.34(1.64-4.35)$ & $0.07^{\prime}$ \\
\hline $\operatorname{ESR}^{++}$(mm/hour) & $23.5(11-82)$ & $47(9-141)$ & 0.41 \\
\hline $\mathrm{CRP}^{*+1}(\mathrm{mg} / \mathrm{dL})$ & $0.70(0.1-3.3)$ & $4.67(0.1-194)$ & 0.00 \\
\hline NLR & $2.87(0.14-9.29)$ & $4.51(0.57-25.85)$ & 0.00 \\
\hline SLICC/ACR Index ${ }^{++++}$ & $0(0-2)$ & $0(0-6)$ & 0.15 \\
\hline \multicolumn{4}{|c|}{$\begin{array}{l}\text { : Blood Ureum Nitrogen } \\
\text { : Erythrocyte Sedimentation Rate } \\
\text { : C-reactive protein } \\
\text { Damage Index } \\
\text { : Adjusted for Disease Activity }\end{array}$} \\
\hline
\end{tabular}

Abstract 159 Tabel 2 Bivariate analysis between several parameters and SLAM score

\begin{tabular}{lcc}
\hline Parameter & SLAM Score & $\mathrm{p}$ \\
\hline NLR & $\mathrm{r:}: 0.249^{\circ}$ & 0.04 \\
Age & $\mathrm{r}:-0.224$ & 0.06 \\
Duration of discase & $\mathrm{r}-0.295^{\circ}$ & 0.01 \\
ESR & $\mathrm{r}: 0.443^{\circ}$ & 0.00 \\
CRP & $\mathrm{r}: 0.319$ & 0.06 \\
\hline
\end{tabular}

$\because$ Significant correlation based on Spearman's Correlation Test (two tail hypothesis, $\mathrm{p}<0.05$ )

$\mathrm{p}<0.01 ; \quad 2.873 \quad(0.14-9.29)$ vs $4.51 \quad(0.57-25.85), \quad \mathrm{p}<0.01]$ Positive correlation was observed between NLR and SLAM score $(r=0.249, \mathrm{p}<0.038)$ with Spearman's correlation test. Analysis with ROC curve revealed the cut-off value of NLR was 3.17 (AUC $0.684, \mathrm{p}<0.02$, 95\% CI $0.55-0.813$, sensitivity $69 \%$, specificity $58 \%$ ).

Conclusions NLR is correlated to disease activity and a promising tool for assessing disease activity in Indonesian SLE patients.

\section{DYSLIPIDEMIA AND DISEASE ACTIVITY IN SYSTEMIC LUPUS ERYTHEMATOUS: AN INDEPENDENT RISK FACTOR}

H Gunawan*, A Awalia, J Soeroso. Airlangga University, Internal Medicine Department Rheumatology Division, Surabaya, Indonesia

\subsection{6/lupus-2017-000215.160}

Background and aims Systemic Lupus Erythematosus (SLE) patients have been associated with increased cardiovascular morbidity and mortality due to atherosclerosis. Dyslipidemia, a traditional atherosclerosis risk factor, has been reported as a long-term independent risk factor in SLE patients. Patients 